\title{
Cholinium-Based lonic Liquids from Hydroxycinnamic Acids as New Promising Bioactive Agents: A Combined Experimental and Theoretical Investigation
}

Monica Demurtas, Valentina Onnis, Paolo Zucca, Antonio Rescigno, Joanna Izabela Lachowicz, Leon De Villiers Engelbrecht, Mariella Nieddu, Guido Ennas, Alessandra Scano, Francesca Mocci,* and Flaminia Cesare Marincola*

Cite This: ACS Sustainable Chem. Eng. 2021, 9, 2975-2986

Read Online

\section{ACCESS | Lلll Metrics \& More | 回 Article Recommendations | SI Supporting Information}

ABSTRACT: Cholinium-based ionic liquids (Cho-ILs) are very attractive compounds for medicinal and pharmaceutical applications as bioavailability enhancers in drug formulations and active components in pharmaceutical ingredients. In this study, we synthesized six Cho-ILs from hydroxycinnamic acids (HCA) ([Cho][HCA] ILs), a group of bioactive compounds with poor water solubility. [Cho][HCA] ILs and their parent acids were evaluated for solubility, thermal stability, and antioxidant activity. Furthermore, [Cho][HCA] ILs were screened for their cytotoxicity. To rationalize the experimental antioxidant activities, density functional theory (DFT) calculations were performed. The theoretical approach allowed for identification of the most likely radical scavenging mechanisms involving HCAs and the corresponding ionic forms under the studied experimental

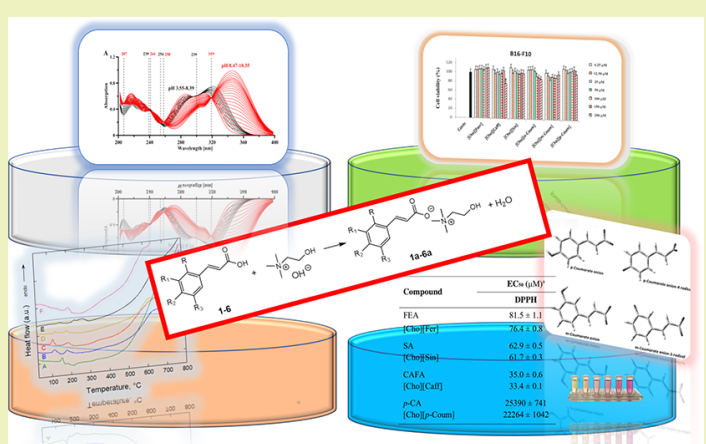
conditions and to rationalize the observed activity differences between salts and acids. Overall, our results revealed a higher solubility and free-radical scavenging activity for [Cho][HCA] ILs than corresponding HCAs, a relatively high thermal stability (melting temperature $>100{ }^{\circ} \mathrm{C}$ ) and negligible cytotoxicity activity. Furthermore, DFT calculations showed that both the hydrogen atom transfer and the sequential proton loss electron transfer mechanisms are likely to occur in aqueous and ethanolic solutions. The picture emerging from our results supports the increasingly expressed idea that [Cho][HCA]ILs are promising candidates for applications in pharmaceutical formulation.

KEYWORDS: cholinium-based ionic liquids, hydroxycinnamic acids, potentiometry, solubility, antioxidant activity, thermal stability, DFT

\section{INTRODUCTION}

Ionic liquids (ILs) are organic salts with a melting point below $100{ }^{\circ} \mathrm{C}$. Due to this feature, ILs are also known as "molten salts." The remarkable properties of ILs, including extremely low vapor pressure, high thermal stability, wide temperature range as liquids, and tunable physicochemical characteristics, ${ }^{1-5}$ make them suitable as solvents and/or reagents in many areas such as organic synthesis, catalysis, biocatalysis, and biomass pretreatment. More recently, the tunable nature of ILs has made these salts very attractive also in the pharmaceutical field, ${ }^{6}$ where, in particular, cholinium-based ILs (Cho-ILs) are receiving great attention. ${ }^{7}$ Cho-ILs can be generated by anion exchange with environmentally friendly materials such as commercially available choline chloride or choline hydroxide and selecting suitable anion species (alkylcarboxylates, aminoacids, and organic acid-derived anions). ${ }^{8}$ Being more biodegradable and less toxic than other common ILs (e.g., pyridinium- and imidazolium-based ILs), they have been proposed not only as convenient catalytic media for drug synthesis but also as bioavailability enhancers in drug formulations and components in active pharmaceutical ingredients (APIs).

Hydroxycinnamic acids (HCAs) are a group of phenolic products of plant secondary metabolism. They all originate from phenylalanine and tyrosine and are present in nature as six molecules: caffeic, ferulic, sinapic, $o$-coumaric, $m$-coumaric, and $p$-coumaric acids. ${ }^{9}$ HCAs and their derivatives have been widely studied for their numerous biological properties, such as antioxidant, anti-inflammatory, anti-microbial, anti-collagenase, and anti-melanogenic activity. ${ }^{10-12}$ The beneficial effects displayed by these compounds have been mainly attributed to the presence of multiple hydroxyl groups and an extended pattern of conjugated double bonds between the phenolic

Received: January 5, 2021

Revised: January 22, 2021

Published: February 10, 2021 
Scheme $1^{a}$<smiles>[R3]c1cc(/C=C/C(=O)O[CH2+][N+](C)(C)CCO)c([R])c([R])c1[R]</smiles>

\begin{tabular}{|c|c|c|c|c|c|}
\hline $\mathbf{R}$ & $\mathbf{R}_{\mathbf{1}}$ & $\mathbf{R}_{\mathbf{2}}$ & $\mathbf{R}_{3}$ & HCA & [Cho][HCA] IL \\
\hline $\mathrm{H}$ & $\mathrm{OMe}$ & $\mathrm{OH}$ & $\mathrm{H}$ & 1 Ferulic acid (FA) & 1a Cholinium ferulate $([\mathrm{Cho}][\mathrm{Fer}])$ \\
\hline $\mathrm{H}$ & $\mathrm{OMe}$ & $\mathrm{OH}$ & OMe & 2 Sinapic acid $(\mathrm{SA})$ & 2a Cholinium sinapate $([\mathrm{Cho}][\mathrm{Sin}])$ \\
\hline $\mathrm{H}$ & $\mathrm{OH}$ & $\mathrm{OH}$ & $\mathrm{H}$ & 3 Caffeic acid (CAFA) & 3a Cholinium caffeate ([Cho][Caff]) \\
\hline $\mathrm{OH}$ & $\mathrm{H}$ & $\mathrm{H}$ & $\mathrm{H}$ & $4 o$-Coumaric acid $(o$-CA) & 4a Cholinium $o$-coumarate $([\mathrm{Cho}][o$-Coum $])$ \\
\hline $\mathrm{H}$ & $\mathrm{OH}$ & $\mathrm{H}$ & $\mathrm{H}$ & $5 m$-Coumaric acid $(m$-CA) & 5a Cholinium $m$-coumarate $([\mathrm{Cho}][m$-Coum $])$ \\
\hline $\mathrm{H}$ & $\mathrm{H}$ & $\mathrm{OH}$ & $\mathrm{H}$ & $6 p$-Coumaric acid $(p-\mathrm{CA})$ & 6a Cholinium $p$-coumarate $([$ Cho $][p$-Coum $])$ \\
\hline
\end{tabular}

${ }^{a}$ Reagents and conditions for the synthesis of [Cho] [HCA] ILs (1-6a): (i) methanol, $0{ }^{\circ} \mathrm{C}$ then, r.t. $3 \mathrm{~h}$.

moiety and the carboxylic group. ${ }^{13}$ The attractive features of HCAs have made them very popular as ingredients in cosmetic and pharmaceutical development. ${ }^{14}$ However, their low water solubility represents a major drawback for their incorporation into hydrophilic topical formulations, ${ }^{11,15}$ and thus, the search for new formulations with enhanced water solubility is of high priority in current research.

Recently, ILs containing cholinium cations combined with HCA-based anions ([Cho][HCA] ILs) have been proposed as promising compounds that are themselves APIs with potential applications in the formulation of pharmaceutical and cosmetic products due to their higher water solubility and antioxidant properties compared to their acidic precursors. ${ }^{16}$ Furthermore, inclusion of phenolic cholinium-based ILs into bacterial cellulose membranes has been proposed as an innovative and biocompatible option for the biomedical industries. ${ }^{17}$

The present study is focused on the synthesis and analysis of the physicochemical properties and antioxidant activity of a new series of Cho-ILs derived from different HCAs, that is, ferulic, sinapic, $o$-coumaric, $m$-coumaric, and $p$-coumaric acids. For the sake of comparison with the literature, ${ }^{16}$ caffeic acid was also included. In particular, for all cholinium salts and the corresponding parent acids, we measured the maximum solubility by UV spectroscopy and the melting point and decomposition temperatures by a combined use of thermogravimetric analysis (TGA) and differential scanning calorimetry (DSC). Furthermore, the antioxidant activity of compounds was evaluated by using 2,2-diphenyl-2-picrylhydrazyl hydrate (DPPH) free radical, while the in vitro cytotoxic study of [Cho][HCA] ILs was conducted by the 3-(4,5dimethylthiazol-2-yl)-2,5-diphenyltetrazolium bromide (MTT) assay method. To gain an insight into the possible free-radical scavenging mechanisms of hydroxycinnamates and their parent acids, density functional theory (DFT) calculations were carried out both in the gas phase and taking into account the solvating environment by means of a polarizable continuum model (PCM) of the two solvents used in the radical scavenging experiment, that is, water and ethanol.

\section{EXPERIMENTAL SECTION}

Materials. Cholinium hydroxide $([\mathrm{Cho}] \mathrm{OH}$, in water solution at 46 wt \%), trans-caffeic acid (98 wt \% of purity), trans-ferulic acid (99 wt \% of purity), DPPH, methanol (99.8 wt \% of purity), ethyl acetate ( 99.8 wt \% of purity), acetone ( 99.9 wt \% of purity), and reagents for potentiometric-spectrophotometric titration $(\mathrm{HCl}, \mathrm{NaCl}$, and $\mathrm{KOH})$ were purchased from Sigma-Aldrich. Sinapic (98 wt \% of purity), $p$ coumaric ( $98 \mathrm{wt} \%$ of purity), trans-m-coumaric ( $99 \mathrm{wt} \%$ of purity), and trans-o-coumaric (98 wt \% of purity) acids were purchased from Alfa Aesar. Deuterated dimethyl sulfoxide (DMSO- $d_{6}, 99.9$ atom \% D) was purchased from Cambridge Isotope Laboratories, Inc. Carbonate free potassium hydroxide solutions were prepared according to the literature. ${ }^{18}$

Synthesis of Cholinium-Hydroxycinnamate ILs. Six cholinium-based ILs derived from $\mathrm{HCA}_{S}$ ([Cho][HCA] ILs) were synthesized according to the procedure described in Scheme 1. The methanolic solution of each HCA (1.1 equivalents) was cooled in an ice bath, then [Cho] OH ( 1 equiv $46 \mathrm{wt} \%$ in a water solution) was added dropwise. The resulting mixture was stirred for $3 \mathrm{~h}$ in the dark at room temperature. The solvent was evaporated under vacuum. In order to remove the unreacted acid, the solid [Cho][Caff] was further washed with acetone and filtered, while the others [Cho][HCA] ILs were subjected to extraction with ethyl acetate. ${ }^{19}$ The residual solvents were evaporated at reduced pressure at $60{ }^{\circ} \mathrm{C}$, and the residual water was removed by freeze drying for $12 \mathrm{~h}$ before each utilization or characterization. The identity and purity of cholinium salts were confirmed by IR, NMR spectroscopy, and elemental analyses. NMR spectra were acquired using a Bruker ADVANCE III HD 600 spectrometer. The NMR chemical shifts $(\delta)$ are reported in parts per million downfield from tetramethylsilane, which was used as an internal standard, and the spectra were recorded in DMSO- $d_{6}$. IR spectra were recorded on a Vector 22 spectrometer (Bruker, Bremen, Germany) in Nujol mulls. Elemental analyses were performed by using a PerkinElmer series II-2400 CHNS/O analyzer. Spectroscopic data are reported in Supporting Information (Figure S1). All salts showed IR and NMR spectra, in agreement with the assigned structures.

Protonation Equilibria. Protonation equilibria of HCAs were investigated by a combination of potentiometric and spectrophotometric methods, as previously described. ${ }^{18,20}$ Briefly, the acid-base titrations were performed in $0.1 \mathrm{M} \mathrm{NaCl}$ at $298.1 \pm 0.1 \mathrm{~K}$ using an automated Titrando 905 Metrohm titrator. The thermostated glass cell was equipped with a magnetic stirrer system, a Metrohm LL 60234100 UNITRODE glass electrode, a microburet delivery tube, and an inlet-outlet tube for argon. The combined Metrohm 6.0262.100 electrode was calibrated as a hydrogen-ion concentration probe by titrating previously standardized amounts of $\mathrm{HCl}$ with $\mathrm{CO}_{2}$ free $\mathrm{NaOH}$ solutions and determining the equivalent point by Gran's method, ${ }^{21}$ which gives the standard potential, $E^{\circ}$, and the ionic 
Table 1. Chemical Equations of HAT, SPLET, and SEPT Mechanisms and the Corresponding TPs Calculated for the Antioxidant Species

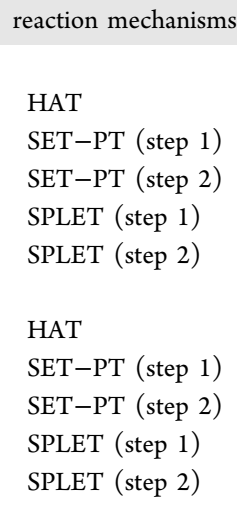

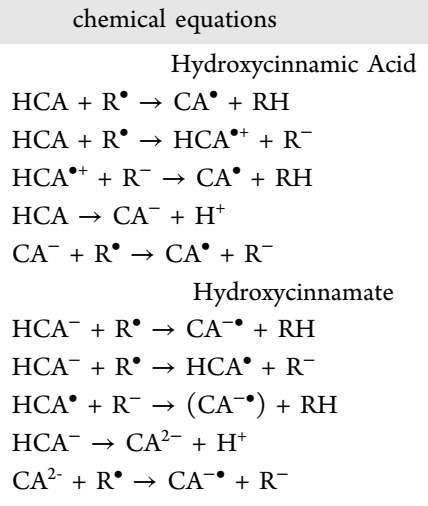

TPs

$$
\begin{aligned}
& \mathrm{BDE}=H\left(\mathrm{CA}^{\bullet}\right)+H\left(\mathrm{H}^{\bullet}\right)-H(\mathrm{HCA}) \\
& \mathrm{IP}=H\left(\mathrm{HCA}^{+\bullet}\right)+H\left(\mathrm{e}^{-}\right)-H(\mathrm{HCA}) \\
& \mathrm{PDE}=H\left(\mathrm{CA}^{\bullet}\right)+H\left(\mathrm{H}^{+}\right)-H\left(\mathrm{HCA}^{\bullet+}\right) \\
& \mathrm{PA}=H\left(\mathrm{CA}^{-}\right)+H\left(\mathrm{H}^{+}\right)-H(\mathrm{HCA}) \\
& \mathrm{ETE}=H\left(\mathrm{CA}^{\bullet}\right)+H\left(\mathrm{e}^{-}\right)-H\left(\mathrm{CA}^{-}\right) \\
& \mathrm{BDE}=H\left(\mathrm{CA}^{-\bullet}\right)+H\left(\mathrm{H}^{\bullet}\right)-H\left(\mathrm{HCA}^{-}\right) \\
& \mathrm{IP}=H\left(\mathrm{HCA}^{\bullet}\right)+H\left(\mathrm{e}^{-}\right)-H\left(\mathrm{HCA}^{-}\right) \\
& \mathrm{PDE}=H\left(\mathrm{CA}^{-}\right)+H\left(\mathrm{H}^{+}\right)-H\left(\mathrm{HCA}^{\bullet}\right) \\
& \mathrm{PA}=H\left(\mathrm{CA}^{2-}\right)+H\left(\mathrm{H}^{+}\right)-H\left(\mathrm{HCA}^{-}\right) \\
& \mathrm{ETE}=H\left(\mathrm{CA}^{-\bullet}\right)+H\left(\mathrm{e}^{-}\right)-H\left(\mathrm{CA}^{2-}\right)
\end{aligned}
$$

product of water $\left[\mathrm{p} K_{\mathrm{w}}=13.74(1)\right.$ in $0.1 \mathrm{M} \mathrm{NaCl}$ at $\left.298.1 \mathrm{~K}\right]$. The working molecule concentration was $3.0 \times 10^{-4} \mathrm{M}$. Measurements were carried out with the use of a Varian Cary 50 UV-vis spectrophotometer Dissolution System in the 200-400 nm spectral range, using $0.2 \mathrm{~cm}$ optical path length. Protonation data were analyzed using HyperQuad2013 (http://www.hyperquad.co.uk/ HQ2013.htm) and Hyss and HypSpec (www.hyperquad.co.uk/ HypSpec2014.htm) programs.

Water Solubility. The maximum water solubility of HCAs and their corresponding cholinium salts was determined by UV spectroscopy. The spectrophotometric measurements were performed by a Varian Cary $50 \mathrm{UV}$-vis spectrophotometer. The saturated aqueous solutions of acids/HCAs and corresponding salts were equilibrated at constant temperature $(298.0 \pm 0.5 \mathrm{~K})$ and under agitation for $10 \mathrm{~min}$. After the equilibration time, all samples were centrifuged at $298.0 \pm$ $0.5 \mathrm{~K}$ for $10 \mathrm{~min}$ at $6000 \mathrm{rpm}$. Each solution was properly diluted before analysis, and the $\mathrm{pH}$ was measured (Supporting Information, Table S2) with the Metrohm LL 60234100 UNITRODE glass electrode calibrated daily with Gran's method. ${ }^{21}$ The product concentrations were calculated on the base of Lambert-Beer equation $(A=c \cdot \varepsilon \cdot l$, where $A$ is the absorption at proper wavelength, $c$ corresponds to the molar concentration, $\varepsilon$ is the molar absorptivity coefficient, and $l$ is the path length expressed in $\mathrm{cm}$ ). Due to variability of UV spectra of each studied molecule as a function of $\mathrm{pH}$, the wavelength $(\lambda[\mathrm{nm}])$ at isosbestic point was chosen for analysis. The isosbestic point corresponds to the wavelength at which the total absorbance of the samples is constant. Since each protonation state of the molecule had different isosbestic points (Supporting Information, Figures S2 and S3), the proper isosbestic points were chosen on the base of the $\mathrm{pH}$ of the analyzed solution (properly diluted before the measurement in order to obtain absorption values in the $0-1$ range). Triplicate measurements were performed.

Thermal Characterization. A PerkinElmer STA6000 instrument was used to carry out simultaneous TGA and DSC at atmospheric pressure and under a nitrogen flow of $60 \mathrm{~mL} \mathrm{~min}^{-1}$. A total of $5 \mathrm{mg}$ of each compound was placed in an alumina crucible, and measurements were performed in the temperature range of $30-800{ }^{\circ} \mathrm{C}$ (heating rate of $\left.10{ }^{\circ} \mathrm{C} \mathrm{min}^{-1}\right)$. Standard samples were used to calibrate the instrument (temperature accuracy of $\pm 1{ }^{\circ} \mathrm{C}$ ).

Antioxidant Activity. The antioxidant activity of HCAs and [Cho] [HCA] ILs was measured by the DPPH assay. The principle of the method is based on the color change of the DPPH solution when the radical is quenched by the antioxidant. Namely, when DPPH solution is mixed with an antioxidant substance, the reduced form of DPPH is obtained and the violet solution turns yellow. This color change was monitored at $515 \mathrm{~nm}$ using an UltroSpec 2100 pro (Amersham Bioscience, Milan, Italy). The scavenging activity of HCAs and [Cho][HCA] ILs on the DPPH radical was determined following the method described by Huang et al. ${ }^{22}$ Briefly, $700 \mu \mathrm{L}$ of a DPPH ethanol solution $(25 \mathrm{mg} / \mathrm{L})$ was mixed with $300 \mu \mathrm{L}$ of a stock solution (with a known concentration) of each compound at different concentrations. The assay was performed in triplicates. A corresponding blank solution was prepared by mixing $700 \mu \mathrm{L}$ of a DPPH aqueous solution and $300 \mu \mathrm{L}$ of distilled water. The samples were incubated for $30 \mathrm{~min}$ in the dark at room temperature, and then, the absorbance at $515 \mathrm{~nm}$ was measured. The radical scavenging activity (RSA) was calculated as a percentage of DPPH discoloration using eq 1

$$
\% \mathrm{RSA}=\left[\left(A_{\mathrm{DPPH}}-A_{\mathrm{S}}\right) / A_{\mathrm{DPPH}}\right] \times 100
$$

where $A_{\mathrm{S}}$ is the absorbance of the solution when the compound is added at a particular level and $A_{\mathrm{DPPH}}$ is the absorbance of the blank solution. The concentration providing 50\% of RSA (EC50) was calculated from the graph of RSA percentage against the concentration by semilog regression analysis in GraphPad PRISM v8 (GraphPad software, San Diego, CA, USA) software.

Cell Line and Culture Conditions. B16-F10 murine melanoma cells were obtained from the Interlab Cell Line Collection (IRCCS Azienda Ospedaliera Universitaria San Martino-IST Istituto Nazionale per la Ricerca sul Cancro Genova, Italy). The 3T3 murine fibroblast cell line was kindly provided by Dr. A. Diana, University of Cagliari. Subcultures of cell line were grown in a $75 \mathrm{~cm}^{2}$ culture flask in phenol red-free Dulbecco's modified Eagle's medium (Invitrogen, USA) with high glucose, supplemented with $10 \%$ fetal bovine serum, $2 \mathrm{mM}$ L-glutamine, penicillin $(100 \mathrm{U} / \mathrm{mL})$, and streptomycin $(100$ $\mu \mathrm{g} / \mathrm{mL}$ ) at $37{ }^{\circ} \mathrm{C}$ in $5 \% \mathrm{CO}_{2}$.

In Vitro Cytotoxicity. The cytotoxic effect of [Cho][HCA] ILs was evaluated in B16-F10 and 3T3 cells by using the MTT assay, based on the cleavage of the tetrazolium salt by mitochondrial dehydrogenases in viable cells. ${ }^{23}$ In brief, $3 \times 10^{4}$ and $3 \times 10^{5}$ cells/ $\mathrm{mL} \mathrm{B16-F10} \mathrm{and} \mathrm{3T3} \mathrm{cells,} \mathrm{respectively,} \mathrm{in} 100 \mathrm{~mL}$ of medium were seeded into a 96-well plate and incubated for $24 \mathrm{~h}$ at $37 \mathrm{C}^{\circ}$. After $48 \mathrm{~h}$ incubation, various concentrations ranging from 6.2 to $200 \mu \mathrm{M}$ of each salt were added to cultures and incubated for additional $24 \mathrm{~h}$ at $37 \mathrm{C}^{\circ}$. Then, an $8 \mu \mathrm{L}$ portion of MTT solution $\left(5 \mathrm{mg} / \mathrm{mL}\right.$ in $\left.\mathrm{H}_{2} \mathrm{O}\right)$ was added and left for $4 \mathrm{~h}$ at $37^{\circ} \mathrm{C}$. The cells were lysed with $100 \mu \mathrm{L}$ of DMSO, and color development was measured at $570 \mathrm{~nm}$ with an Infinite 200 auto microplate reader (Infinite 200, Tecan, Austria). The absorbance was proportional to the number of viable cells.

Statistical Analysis. All the experiments were carried out in triplicate. The results were expressed as means $\pm \mathrm{SD}$ and evaluated by analysis of variance followed by Bonferroni post-test carried out on GraphPad PRISM v8 (GraphPad software, San Diego, CA, USA) software. Differences were considered significant at $p<0.05$.

Antioxidant Mechanisms. Three well-known antioxidant mechanisms ${ }^{24-26}$ were investigated to elucidate the radical scavenging processes of the hydroxycinnamates $\left(\mathrm{HCAs}^{-}\right)$and the corresponding acid precursors (HCAs): the hydrogen atom transfer (HAT), singleelectron transfer-proton transfer (SET-PT), and sequential proton loss electron transfer (SPLET). Taking into account the steric crowding around the divalent nitrogen atoms in the DPPH radical, 

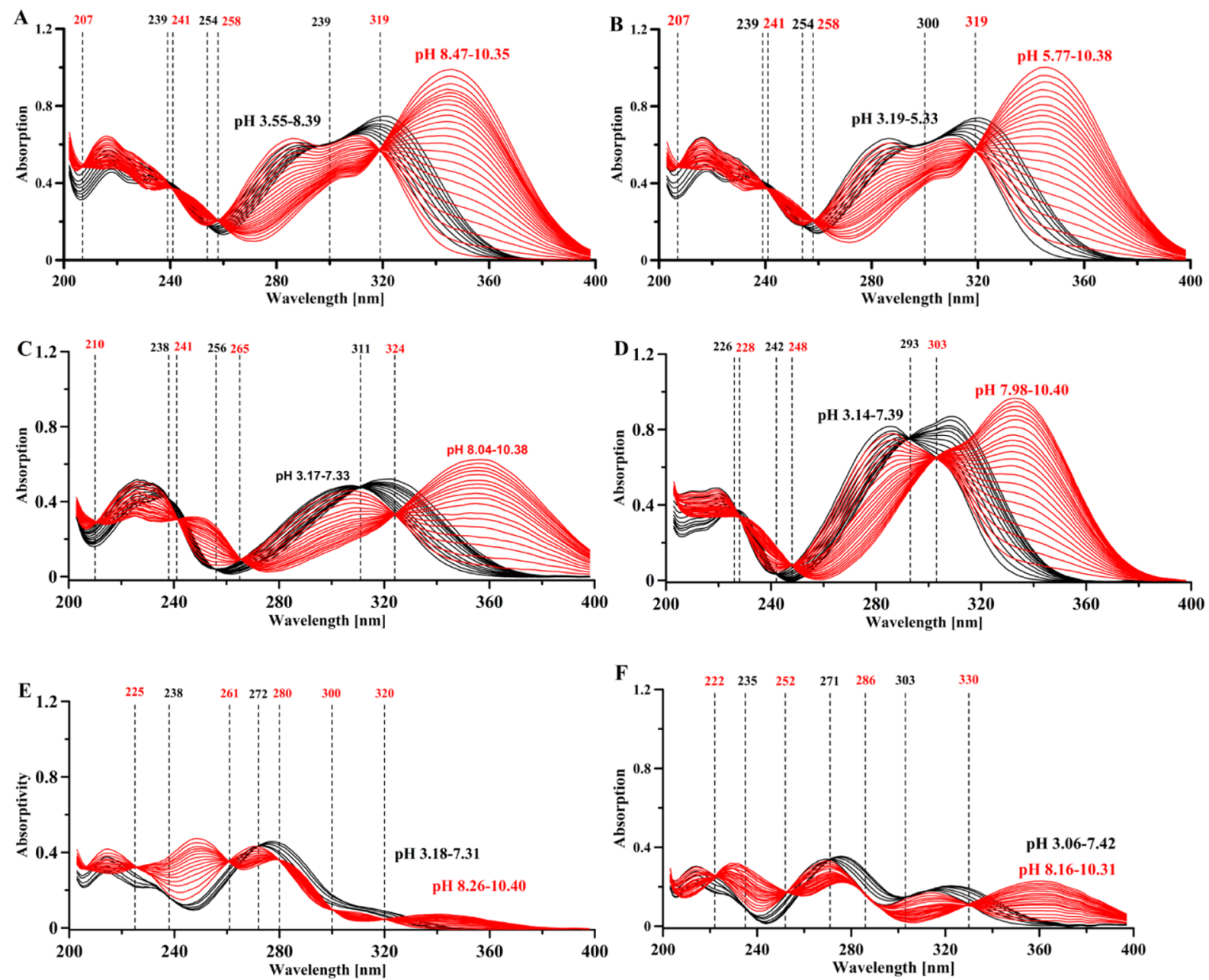

Figure 1. UV spectra of (A) caffeic, (B) ferulic, (C) sinapic, (D) p-coumaric, (E) $m$-coumaric, and (F) $o$-coumaric acids. Isosbestic points are signed as a dashed line.

the radical adduct formation mechanism was not considered in the calculations.

Table 1 schematizes the reaction mechanisms for HAT, SET-PT, and SPLET and the equations of the related thermodynamic parameters (TPs). We note that the total enthalpy of each reaction comprises the TPs of both the antioxidant and the particular radical species $\left(\mathrm{R}^{\bullet}\right)$ considered. Because, in this study, we focused on comparing the reactivity of the HCAs with the corresponding hydroxycinnamates and the reactivity between different species of the same class, we limit our attention to the antioxidant species, following the procedure already applied on similar systems. ${ }^{27-30}$

As shown in Table 1, HAT is a single-step mechanism involving the formal transfer of a hydrogen atom from the radical scavenger to a reactive radical $\left(\mathrm{R}^{*}\right)$ and thus the formation of a radical by the loss of a phenolic hydrogen atom in $\mathrm{HCA}$ and $\mathrm{HCA}^{-}$(i.e., $\mathrm{CA}^{\bullet}$ and $\mathrm{CA}^{-}$, respectively, as listed in Table 1). An important parameter to evaluate the probability of the antioxidant action through the HAT mechanism is the bond dissociation enthalpy (BDE) of the phenolic $\mathrm{O}-\mathrm{H}$ bond which releases the hydrogen. Compounds having the hydroxyl group(s) with lower BDE values are expected to be the most active with the HAT mechanism. Since the $\mathrm{OH}$ of the carboxylic group is known to have $\mathrm{BDE}$ higher than that of phenolic $\mathrm{OH}^{31}$ the involvement of the carboxylic group in the radical scavenging has not be taken into account.

SET-PT is a double-step mechanism (Table 1). The first step involves the loss of one electron, and it is thus related to the ionization potential (IP). In the second and last step, the transfer of a proton from the radical formed in the first step occurs and it is thus correlated to the proton dissociation enthalpy (PDE).
SPLET is a multistep mechanism. The first step is the proton loss (step 1 in Table 1), and its energy depends on the proton affinity (PA) of the antioxidant. The second step involves the transfer of an electron, thus it is correlated to the electron transfer enthalpy (ETE). The third and last step is the protonation of the anion formed in the previous step.

To calculate the TPs related to the considered steps of the three mechanisms, we performed quantum mechanical calculations based on the DFT to optimize the involved species: $\mathrm{H}^{\circ}, \mathrm{HCA}, \mathrm{HCA}^{-}, \mathrm{CA}^{-}$, $\mathrm{CA}^{2-}, \mathrm{CA}^{\bullet}, \mathrm{CA}^{-\bullet}, \mathrm{HCA}^{\bullet}$, and $\mathrm{HCA}^{\bullet+}$ and to perform the vibrational analysis. The calculated gas phase enthalpy of a proton and electron is 1.483 and $0.752 \mathrm{kcal} / \mathrm{mol}$, respectively. Proton and electron solvation enthalpies were taken from Rimarćik et al.'s report and references therein $^{32}$ and are summarized in Supporting Information (Table S3).

DFT Calculations. The structures of all of the studied HCAs, $\mathrm{HCAs}^{-}$, and the intermediate species involved in the abovementioned mechanisms were optimized by means of DFT calculations. In detail, geometry optimization was performed employing the unrestricted B3LYP functional as implemented in the commercially available suite of programs Gaussian $16,{ }^{33}$ using the $6-311++G(d, p)$ basis set for all atoms. The same level of theory was used to perform the vibrational analysis on all of the optimized structures in order to verify the character of the stationary points (no imaginary frequencies were found) and to compute the TPs at $298.15 \mathrm{~K}$. For each compound and oxidation state, the global minimum in vacuo was identified through a relaxed potential energy scan performed around all of the rotatable bonds, with steps of $180^{\circ}$. Spin contamination in the radicals was low, always under 0.8 , and in all of the optimizations, the annihilation of the first spin contaminant led to the value 0.75 . 
The solvent effect on the geometry and on the electronic properties was estimated by further optimizing the in vacuo global minimum structure of each species using a PCM in the current implementation in Gaussian 16, performing a reaction field calculation using the integral equation formalism. ${ }^{34,35}$ All PCM calculations were carried out at $298.15 \mathrm{~K}$, and the molecular cavity was constructed using the default procedure in which the radii of the spheres placed around each atom are derived from the Universal Force Field (UFF) force field and scaled by a factor of 1.1. The same calculations were performed using the relatively recent Minnesota hybrid meta exchangecorrelation functionals M06-2X of Zhao and Truhlar, ${ }^{36}$ which is increasingly used in the study of antioxidant compounds. ${ }^{37,38}$ Graphics of molecular models were generated using GaussView6. ${ }^{39}$

\section{RESULTS AND DISCUSSION}

Protonation Equilibria and Water Solubility. Solubility is one of the important parameters of a drug to achieve desired availability for the required pharmaceutical response. The extent of solubility in a specific solvent is expressed as the concentration of the solute in a saturated solution at a given temperature. From the chemical point of view, $[\mathrm{Cho}][\mathrm{HCA}]$ ILs represent the bases whose acidic forms are poorly soluble in water. The solubility of an acid or base is dependent on its ionization constants and the maximum solubility of the various species of the compound. ${ }^{40,41}$ Moreover, the solubility profile of the protonated molecules depends directly on solution $\mathrm{pH}$. Introduction of salts to a saturated solution often alters the solubility of the compound. Such a change in solubility depends on solubility product effects and changes in the activity coefficients. ${ }^{42}$

In the present study, the protonation equilibria of the six HCA precursors of the cholinium-based ILs under investigation (i.e., compounds $\mathbf{1 - 6}$ in Scheme 1) were studied by combined potentiometric-spectrophotometric measurements. Experiments were performed over a $\mathrm{pH}$ range of 3-11. The UV spectra of the titration analyte solutions were characterized by different bands and distinct isosbestic points (Figure 1). Based on the analysis of absorptivity bands (calculated with the HypSpec program) (Supporting Information, Figure S2), we propose a common equilibrium model for all studied acids

$$
\mathrm{H}_{2} \mathrm{~L} \leftrightarrow[\mathrm{HL}]^{-} \leftrightarrow[\mathrm{L}]^{2-}
$$

which takes into account two dissociations: the proton dissociation of the carboxylic group, leading to the spectral changes in the acidic $\mathrm{pH}$ range, and the dissociation of the phenolic group, shifting the absorbance bands in the basic $\mathrm{pH}$ range. The third dissociation constant of caffeic acid, associated to the second hydroxyl group, was not observed, being outside the $\mathrm{pH}$ range under investigation (i.e., at $\mathrm{pH}>$ $11) .{ }^{43}$ Caffeic (CAFA), ferulic (FA), sinapic (SA), and $p$ coumaric $(p-\mathrm{CA})$ acids shared common spectral changes (Supporting Information, Figures S2A-D). Their acidic dissociation was characterized by ipso- and ipochromic shifts, while the basic dissociation led to the bato- and iperchromic shifts of the bands. The absorbance bands of $o$-coumaric ( $o$ $\mathrm{CA})$ and $m$-coumaric ( $m$-CA) acids were less intense than those of the other acids. The proton dissociation of both compounds was characterized by the ipsochromic shifts of the bands at acidic $\mathrm{pH}$ and ipso- and batochromic shifts of the bands at basic $\mathrm{pH}$ (Supporting Information, Figures S2E,F). The speciation plots relative to the protonation of the six pure acids are reported in Supporting Information (Figure S3). Compared to the literature data, our experiments provided satisfactory values of the protonation constants (Supporting
Information, Table S1), despite the different experimental conditions of temperature and ionic strength. Furthermore, it can be noted that the acidic and basic dissociation constants are inversely correlated $(R=0.97)$ (Supporting Information, Figure S4). Such a relation can be associated to the formation of intramolecular hydrogen bonds, as previously observed for caffeic acid derivatives ${ }^{44,45}$ and other small molecules. ${ }^{46}$

The solubilities of [Cho][HCA] ILs and their parent acids were measured by UV spectroscopy. Since the absorbance at the isosbestic point is independent of the $\mathrm{pH}$ value of solutions, the solubility was estimated at isosbestic wavelengths (the experimental $\mathrm{pH}$ values of aqueous solutions are reported in Supporting Information, Table S2). Table 2 shows the solubility values of both salts and acidic precursors, expressed as the average of three independent experiments.

Table 2. Solubility ([M]) of HCAs and the Corresponding [Cho][HCA] ILs

$\begin{array}{lc}\text { compound } & \text { solubility }^{a}[\mathrm{M}] \\ \mathrm{FA} & 0.0047 \pm 0.0007 \\ {[\mathrm{Cho}][\mathrm{Fer}]} & 0.6 \pm 0.1 \\ \mathrm{SA} & 0.0028 \pm 0.0002 \\ {[\mathrm{Cho}][\mathrm{Sin}]} & 0.2 \pm 0.1 \\ \text { CAFA } & 0.0040 \pm 0.0006 \\ {[\mathrm{Cho}][\mathrm{Caff}]} & 1.3 \pm 0.1 \\ p \text {-CA } & 0.007 \pm 0.002 \\ {[\mathrm{Cho}][p \text {-Coum }]} & 1.4 \pm 0.1 \\ m \text {-CA } & 0.013 \pm 0.002 \\ {[\mathrm{Cho}][m \text {-Coum }]} & 2.8 \pm 0.5 \\ o \text {-CA } & 0.008 \pm 0.001 \\ {[\mathrm{Chol}][o-\text {-Coum }]} & 2.9 \pm 0.8\end{array}$

${ }^{a}$ Values are means of three determinations \pm standard deviation.

For the phenolic acids, the following order of decreasing solubility was found: $m$-CA $>o$-CA $\approx p$-CA $>$ FA $\approx \mathrm{CAFA}>$ $\mathrm{SA}$. The solubility values were in good agreement with those reported in the literature. ${ }^{47,48}$ As it can be noted, acids with only one hydroxyl group in the aromatic ring have the highest solubility, while the addition of other functional groups $(-\mathrm{OH}$ and/or $-\mathrm{OCH}_{3}$ ) lowers the overall solubility of the molecule. It is noteworthy that this solubility trend correlates linearly with the $\mathrm{pK}$ values of the acids, with the exception of sinapic acid (Supporting Information, Figure S5). Addition of different functional groups leads to the electron-withdrawing or electron-donating effects, as well as resonance effects, which influence the values of protonation constants. ${ }^{49,50}$ The change of protonation state of the molecule, in turn, influences the extent of hydrogen of the molecule with water. In particular, the special proximity of different dissociation groups in the same molecule (e.g., caffeic acid) leads to the formation of intramolecular hydrogen bonds, which not only significantly changes the protonation constant of the neighboring group ${ }^{46,51}$ but also lowers the overall number of hydrogen bonds of the molecule with solvent.

The conversion of HCAs into cholinium-based ILs notably increased the solubility by $2 / 3$ orders of magnitude. This finding agrees with the previous literature data. ${ }^{16}$ Data in Table 2 show that the strongest variation was recorded for the $o$-CA/ [Cho][o-Coum] pair. Compared to the acids, the trend of solubility of salts was slightly different, following the order: $[\mathrm{Cho}][m$-Coum $] \approx[\mathrm{Cho}][o$-Coum $]>[\mathrm{Cho}][p$-Coum $] \approx$ $[\mathrm{Cho}][\mathrm{Caff}]>[\mathrm{Cho}][\mathrm{Fer}]>[\mathrm{Cho}][\mathrm{Sin}]$. Considering that 
both acids and salts have the same mono-protonated state at the $\mathrm{pH}$ of solubility analysis (Supporting Information, Table S2), it is likely that the basic counterpart of the salt influences the overall solubility of the salt.

Thermal Characterization. The thermal stability of [Cho][HCA] ILs and their acidic precursors was investigated by simultaneous TGA and DSC. TGA is a useful technique to investigate the mass loss of a sample upon heating at a given heating rate, while DSC investigates the thermal effect differentiating between phase transformation and decomposition. The reproducible extrapolated melting $\left(T_{M}\right)$ and decomposition $\left(T_{\mathrm{D}}\right)$ onset temperatures were calculated. The results are depicted in Table 3 for all compounds, while the corresponding experimental curves are reported in Supporting Information (Figures S6-S9).

Table 3. Onset Melting $\left(T_{M}\right)$ and Decomposition $\left(T_{D}\right)$ Temperatures of HCAs and $[\mathrm{Cho}][\mathrm{HCA}] \mathrm{ILs}^{a}$

\begin{tabular}{|c|c|c|c|}
\hline \multirow[b]{2}{*}{ compound } & \multicolumn{2}{|c|}{ DSC } & \multirow{2}{*}{$\frac{\text { TGA }}{T_{\mathrm{D}},{ }^{\circ} \mathrm{C}}$} \\
\hline & $T_{\mathrm{M}},{ }^{\circ} \mathrm{C}$ & 2nd $T_{\mathrm{D}},{ }^{\circ} \mathrm{C}$ & \\
\hline FA & 172 & 208 & 211 \\
\hline$[\mathrm{Cho}][\mathrm{Fer}]$ & & & 105 \\
\hline SA & 191 and $198^{b}$ & 226 & 229 \\
\hline$[\mathrm{Cho}][\mathrm{Sin}]$ & & & 103 \\
\hline CAFA & $217^{c}$ & 269 & 216 \\
\hline$[\mathrm{Cho}][\mathrm{Caff}]$ & $141^{c}$ & & 148 \\
\hline$p$-CA & $221^{c}$ & 233 & 212 \\
\hline$[\mathrm{Cho}][p$-Coum $]$ & & & 118 \\
\hline$m-\mathrm{CA}$ & 194 & 242 & 245 \\
\hline$[\mathrm{Cho}][m$-Coum $]$ & & & 132 \\
\hline$o$-CA & $217^{c}$ & 245 & 213 \\
\hline$[\mathrm{Cho}][o$-Coum $]$ & & & 180 \\
\hline
\end{tabular}

${ }^{a}$ Temperature accuracy of $\pm 1{ }^{\circ} \mathrm{C}$. ${ }^{b}$ The first peak is due to phase transformation, and the second peak is due to melting. ${ }^{c}$ Incongruent melting (the decomposition occurs either just after melting is complete or even simultaneously).

Two different endotherm effects were evidenced by the DSC thermograms of HCAs, a first endothermic sharp signal, due to melting, followed by a second large endothermic signal (Supporting Information, Figure S6). Only the DSC thermogram of sinapic acid showed two net endothermic DSC peaks, almost $30{ }^{\circ} \mathrm{C}$ before decomposition, suggesting the presence of a polymorphic transition followed by melting. In good agreement with the literature, ${ }^{52}$ in the DSC curve of caffeic acid, the first endothermic peak is followed by a minor exothermic tail, indicating that another phenomenon excluding melting occurs either just after melting is complete or even simultaneously. It is noteworthy that in TG thermograms of CAFA, $o$-CA, and $p$-CA, the first significant step due to decomposition, characterized by the onset $T_{\mathrm{D}}$ temperature, occurs very close to the melting of the samples observed in DSC thermograms (Table 3), indicating an incongruent melting, that is, the decomposition occurs either just after melting is complete or even simultaneously. ${ }^{53}$

The conversion of HCAs into [Cho][HCA] ILs decreased the onset decomposition temperature (Table 3). Nevertheless, all cholinium salts kept exhibiting a good thermal stability with $\mathrm{T}_{\mathrm{D}}$ values higher than $100{ }^{\circ} \mathrm{C}$. The most stable sample was [Cho][Caff] $\left(T_{D}=148{ }^{\circ} \mathrm{C}\right)$, while the lowest stability was shown by the two ILs containing methoxy groups in the aromatic ring, that is, $[\mathrm{Cho}][\mathrm{Sin}]\left(T_{\mathrm{D}}=103{ }^{\circ} \mathrm{C}\right)$ and
$[\mathrm{Cho}][\mathrm{Fer}]\left(T_{\mathrm{D}}=105^{\circ} \mathrm{C}\right)$. At temperatures higher than 150 ${ }^{\circ} \mathrm{C}$, the TG curves of all samples exhibited further steps indicating a complex decomposition (Supporting Information, Figure S8). Only [Cho][o-Coum $]$ and $[$ Cho $][m$-Coum $]$ showed a slight weight loss at low temperature due to solvent residual or moisture captured by the air during handling. DSC thermograms of [Cho][HCA] ILs confirmed the TGA results (Supporting Information, Figure S9).

Radical Scavenging Activity. To evaluate the antioxidant activity of HCAs and [Cho][HCA] ILs in vitro, their radical scavenging capacity was measured by using the DPPH assay. From the set-activity curves as a function of the concentration of tested compounds, the $\mathrm{EC}_{50}$ (half maximum effective concentration) parameter was estimated. $\mathrm{EC}_{50}$ essentially represents the required concentration for an antioxidant to reach $50 \%$ of scavenging free-radical activity: the lower $\mathrm{EC}_{50}$ value, the higher scavenging free-radical activity of an antioxidant. Table 4 shows the mean $\mathrm{EC}_{50}$ values ( \pm standard

Table 4. Antioxidant Activity of HCAs and [Cho][HCA] ILs against DPPH

\begin{tabular}{lc}
\multicolumn{1}{c}{ compound } & $\mathrm{EC}_{50}(\mu \mathrm{M})^{a}$ \\
FA & $81.5 \pm 1.1$ \\
{$[\mathrm{Cho}][\mathrm{Fer}]$} & $76.4 \pm 0.8$ \\
$\mathrm{SA}$ & $62.9 \pm 0.5$ \\
{$[\mathrm{Cho}][\mathrm{Sin}]$} & $61.7 \pm 0.3$ \\
CAFA & $35.0 \pm 0.6$ \\
{$[\mathrm{Cho}][$ Caff] } & $33.4 \pm 0.1$ \\
$p$-CA & $25.390 \pm 741$ \\
{$[$ Cho][p-Coum $]$} & $22.264 \pm 1042$
\end{tabular}

${ }^{a} \mathrm{EC}_{50}$ for concentration of antioxidant necessary to decrease the initial DPPH radical concentration by $50 \%$. Values are means of three determinations \pm standard deviation.

deviation) of three independent measurements for every compound under investigation but $o$ - and $m$-coumaric acids and the corresponding cholinium salts. Indeed, the DPPH solutions of these latter samples reached discoloration levels lower than $50 \%$ at analyte concentrations higher than $25 \mathrm{mM}$, indicative of a very weak antioxidant activity (14 and 16\% for $m$-CA and [Cho] $[m$-Coum], respectively; 35 and $37 \%$ for $o$ $\mathrm{CA}$ and [Cho][o-Coum], respectively).

Significant differences $(p<0.05)$ were observed among the scavenging activity of HCAs. The results showed the following decreasing order: $\mathrm{CAFA}>\mathrm{SA}>\mathrm{FA}>p$-CA $\gg o$-CA, $m$-CA. Thus, the most potent compound was caffeic acid, while the lowest antioxidant activity was exhibited by $o$-, $m$, and $p$ coumaric acids. Investigations aimed at evaluating the antioxidant activities of cinnamic and benzoic acid derivatives have indicated a structure-activity relationship in the model systems. ${ }^{54}$ As shown by our DFT results (see below), the structures of HCAs and [Cho][HCA] ILs under investigation are nearly planar in solution. Thus, any differences in activity among them should be ascribed to electronic phenomena rather than to steric hindrance effects. According to the literature, ${ }^{54}$ the higher radical scavenging ability of CAFA in comparison to the other HCAs can be explained by the presence of an additional hydroxyl group that increases the resonance stabilization, while SA and FA are more effective than $o$-, $m$-, and $p$-CA due to the electron-donating methoxy group $(s)$ which stabilize the phenoxy radical after hydrogen donation of the hydroxy group. 
Interestingly, the conversion of HCAs into Cho-based ILs influenced positively the RSA. Indeed, as can be seen in Table 4 , all of the synthesized ILs were able to inhibit DPPH freeradical scavenging at $\mathrm{EC}_{50}$ values lower than that measured for the corresponding parent acids. As observed for HCAs, the most efficient cholinium salt was [Cho][Caff]. The possible mechanisms responsible of the antioxidant activities and their relationship with the DPPH experimental results are discussed in detail below, together with the finding of DFT calculations.

MTT Viability Assay. The influence of [Cho][HCA] ILs on the cell viability was determined on murine melanoma B16F10 and murine fibroblast 3T3 cells with the MTT assay. Compounds were tested at concentrations between 6.25 and $200 \mu \mathrm{mol} / \mathrm{L}$. The dose-response cytotoxicity results are depicted in Figure 2. As can be seen, in both cell lines, none
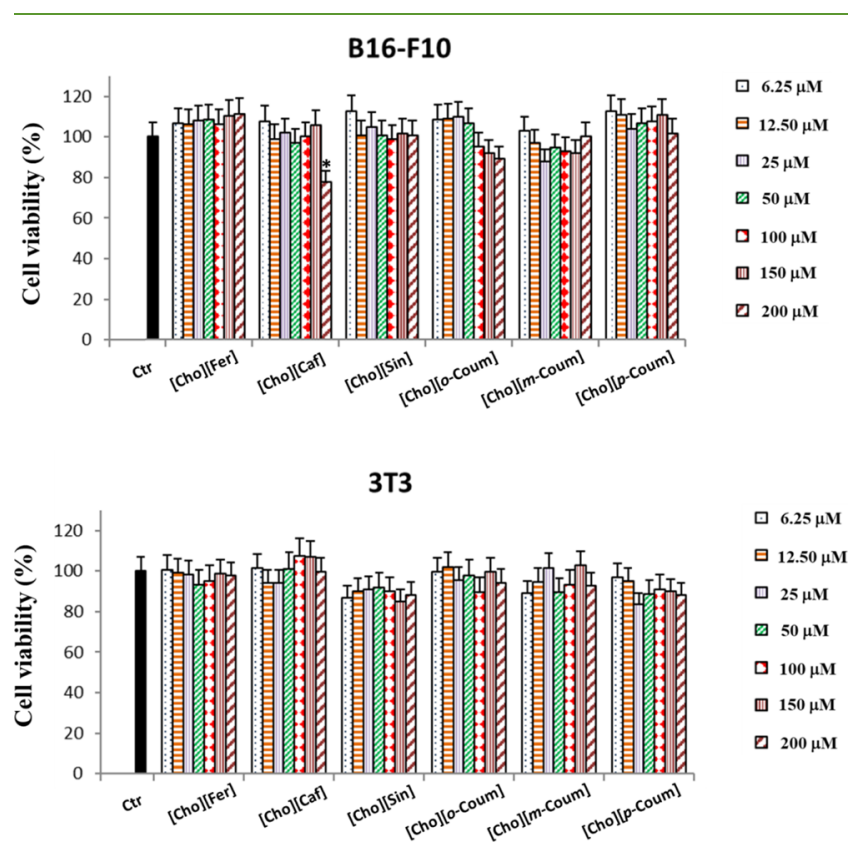

Figure 2. Cell viability results (\%) by the MTT assay of melanoma B16F10 and fibroblast 3T3 cell lines exposed to different concentrations of [Cho][HCA] ILs. Results are expressed as mean $\pm \mathrm{SD}$ values of three observations; $*$ significantly different from control $(p<0.001)$.

of the Cho-based ILs was found to have cytotoxic activity at the concentration under investigation except for [Cho] [Caff] that induced a significant reduction $(p<0.001)$ of B16-F10 tumoral cell viability (22.39\%) at the highest dose.

DFT Results. Conformational Analysis. While many computational studies on HCAs have focused on the antioxidant activity of the undissociated carboxylic acids, ${ }^{25-30,55-60}$ in the present study, we considered also the corresponding carboxylate forms, and HCAs were included mainly for comparative purposes.

A full conformational analysis was performed in vacuo on all of the compounds and on all the intermediates involved in the RSA, as described in the Experimental Section. In Figure 3, the global minima structures obtained for all the species involved in the antioxidative process are represented. Analogous calculations were carried out on HCAs. The number of stable conformers found for each species are reported in the Supporting Information together with their coordinates (Tables S4 and S56).
Computed TPs. The TPs in the gas phase were calculated using exclusively the global minima structures. The calculation of TPs in PCM solvent was performed after subjecting the gas phase global minima to an optimization process in the selected solvating media. The parameters calculated at the B3LYP/6$311++\mathrm{G}(\mathrm{d}, \mathrm{p})$ theory level are collected in Table 5 for both $\mathrm{HCA}^{-}$and HCA species, while those computed with M06-2X/ $6-311++\mathrm{G}(\mathrm{d}, \mathrm{p})$ are reported in Supporting Information (Tables S57-S59). Since the general trends of TPs obtained with the two theory levels are the same (Supporting Information, Figures S10-S12), each mechanism is discussed in the following sections in view of the results obtained with B3LYP/6-311++G(d,p), and the same conclusions hold also for M06-2X, unless otherwise specified. To assist the analysis of the data, the TPs are also plotted in the Supporting Information according to their radical scavenging capability, as observed in the DPPH assay (Figures S13-S17).

HAT Mechanism. As discussed in the Experimental Section, the BDE of the $\mathrm{O}-\mathrm{H}$ bonds in the antioxidant molecule is related to the HAT mechanism: lower the BDE value, easier the $\mathrm{O}-\mathrm{H}$ bond breaking, and higher the antioxidant activity.

In the gas phase, the BDEs obtained for the $\mathrm{HCAs}^{-}$are lower than those obtained taking into account the solvent effects. Such a systematic difference cannot be discerned for the HCAs: for CAFA, FA, and $o$-CA, the solvent inclusion leads to $\mathrm{BDE}$ increase, while for $\mathrm{SA}, p$-CA, and $m$-CA, there is a small decrease. Therefore, while for other compounds, ${ }^{58}$ it was observed that the $\mathrm{O}-\mathrm{H}$ dissociation energy increases on changing from the gas phase to polar media, this cannot be generalized for the undissociated acids in this class of compounds.

In water and ethanol solvents, the $\mathrm{BDE}$ values of $\mathrm{HCAs}^{-}$are lower than those of HCAs. A similar difference between the bond dissociation energy of neutral and anionic form of acids was obtained by Amic et al. ${ }^{58}$ for the dihydrocaffeic and dihydroferulic acids in water. Furthermore, as can be seen in Table 5, for both species, the BDE ranges observed in the ethanol environment almost overlap with those in water. M062X BDEs show the same trend as those computed with B3LYP but with higher values (Supporting Information, Tables S57S59, Figures S10-S12).

For the pairs of compounds caffeate/caffeic acid and sinapate/sinapic acid, the BDE values in PCM solvent are lower than those of the other compounds, in agreement with the experimental data of the DPPH assay. Overall, with the exception of ferulate and ferulic acid, the order of BDEs for HCAs and $\mathrm{HCAs}^{-}$is the same as that of oxidative activity based on the DPPH radical assay.

The good correlation observed between the orders of experimental antioxidant activity and the calculated BDE values suggests that in the presence of the radical $\mathrm{DPPH}$, both HCAs - and HCAs can react with a single-step mechanism of the HAT type. Furthermore, the BDE values indicate that the HAT mechanism is thermodynamically favored for $\mathrm{HCAs}^{-}$ when compared with the corresponding acid.

SET-PT Mechanism. The free-radical scavenging may also occur via SET followed by PT. The first step of SET-PT involves the loss of one electron (Table 1), and it is related to the IP parameter which quantifies the electron donor capability of a molecule. Molecules with lower IP are more susceptible to the electron transfer, and this facilitates reactivity through the SET-PT mechanism. As can be seen in Table 5, the values 

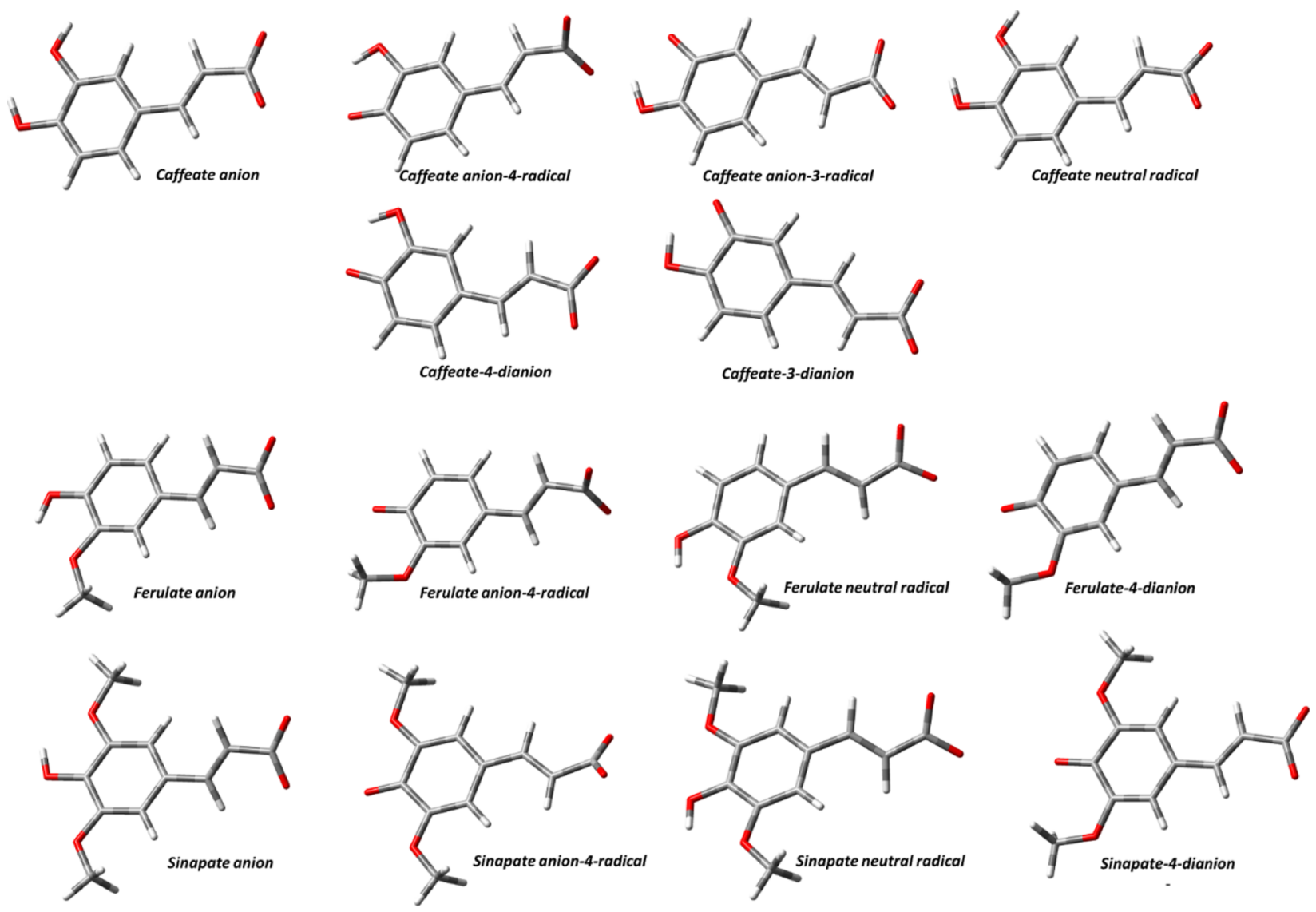<smiles>C=Cc1c(C=C)c(=C)c(C(C)=C(C)C(=C)C)c(C)c1=C</smiles><smiles></smiles><smiles>C=Cc1c(C)c(C)c(=C(C)C(=C)C(=C)C)c(=C)c1C=C</smiles><smiles>C=C(C)C(C)=C(C)c1c(C)c(=C)c(C)c(C)c1=C</smiles><smiles>C=C(C(C)=C(C)C)c1c(C)c(C)c(=C)c(=CC)c1C</smiles><smiles>C=C(C)C(=C)C(=C)c1c(C)c(C)c(=C)c(=C)c1C</smiles><smiles>C=C(C)C(=C)C(C)=c1c(=C)c(C)c(C)c(=CC)c1=C</smiles><smiles>C=C(C)C(C)=C(C)c1c(C)c(=C)c(C)c(C)c1=C</smiles><smiles>C=C(C)C(=C)C1=C(CC)C(=C)C(C)=C(C)C1=O</smiles>
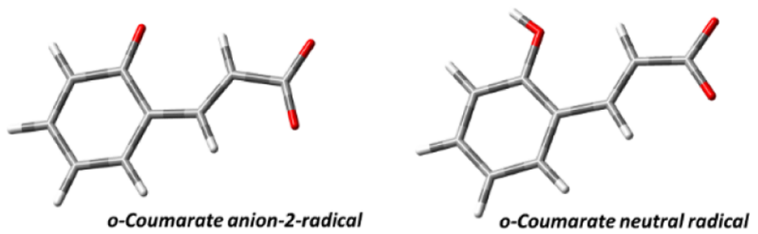<smiles>C=C(C)C(=C)c1c(C)c(=C)c(C)c(C)c1=C(C)C</smiles>

Figure 3. Representation of the global minima of the studied hydroxycinnamates and all the intermediate species involved in the antioxidative process calculated in vacuo at the UB3LYP/6-311++G(d,p).

reported for the coumaric derivatives show that the $-\mathrm{OH}$ group in the para position has the lowest IP values both in the gas phase and in solvent due to the superior stabilization of the radical by resonance in the phenylpropenoic structure, as already observed be Szelag et al. ${ }^{57}$ for other compounds.
In the considered solvents, comparison of the data of HCAs with those of $\mathrm{HCAs}^{-}$shows that the IP is generally lower for the anionic species. This is not surprising since the electron transfer from an anion is expected to be easier than that from a neutral molecule, thus suggesting that the SET-PT mecha- 
Table 5. Thermodynamic Parameters $\left(\mathrm{kcal} \mathrm{mol}^{-1}\right)$ of HCAs and $\mathrm{HCAs}^{-}$at the B3LYP/6-311++G(d,p) Level of Theory Obtained in the Gas Phase, Water, and Ethanol at $298 \mathrm{~K}$

\begin{tabular}{|c|c|c|c|c|c|c|c|c|c|c|c|}
\hline \multirow[b]{2}{*}{ medium } & \multirow[b]{2}{*}{ site } & \multicolumn{5}{|c|}{$\mathrm{HCA}^{-}$} & \multicolumn{5}{|c|}{ HCA } \\
\hline & & $\mathrm{BDE}$ & IP & PDE & $\mathrm{PA}$ & ETE & $\mathrm{BDE}$ & IP & PDE & $\mathrm{PA}$ & ETE \\
\hline & & & & [Caff] & & & & & CAFA & & \\
\hline gas phase & $4-\mathrm{OH}$ & 60.6 & 78.6 & 297.9 & 385.5 & -9.0 & 73.2 & 180.3 & 208.8 & 319.1 & 70.0 \\
\hline & $3-\mathrm{OH}$ & 66.7 & & 304.0 & 387.0 & -4.4 & 75.6 & & 211.2 & 324.7 & 66.8 \\
\hline water & $4-\mathrm{OH}$ & 71.0 & 101.4 & 14.8 & 42.3 & 75.3 & 74.4 & 112.4 & 8.6 & 37.1 & 83.9 \\
\hline & $3-\mathrm{OH}$ & 74.1 & & 17.9 & 44.5 & 76.2 & 76.6 & & 10.8 & 40.8 & 82.4 \\
\hline ethanol & $4-\mathrm{OH}$ & 70.7 & 107.2 & 11.6 & 39.4 & 79.4 & 74.3 & 121.1 & 1.2 & 32.7 & 89.7 \\
\hline & $3-\mathrm{OH}$ & 73.9 & & $\begin{array}{l}14.8 \\
{[\mathrm{Sin}]}\end{array}$ & 41.6 & 80.3 & 76.5 & & $\begin{array}{c}3.4 \\
\text { SA }\end{array}$ & 36.4 & 88.1 \\
\hline gas phase & $4-\mathrm{OH}$ & 67.9 & 77.5 & 306.3 & 395.0 & -11.1 & 77.2 & 170.2 & 222.9 & 328.2 & 65.0 \\
\hline water & $4-\mathrm{OH}$ & 71.3 & 98.2 & 19.6 & 50.1 & 67.7 & 74.0 & 108.0 & 11.1 & 45.8 & 74.8 \\
\hline ethanol & $4-\mathrm{OH}$ & 71.2 & 104.1 & $\begin{array}{l}15.1 \\
{[\mathrm{Fer}]}\end{array}$ & 47.4 & 71.8 & 74.2 & 116.0 & $\begin{array}{c}6.2 \\
\text { FA }\end{array}$ & 41.5 & 80.7 \\
\hline gas phase & $4-\mathrm{OH}$ & 69.3 & 76.9 & 308.3 & 394.6 & -9.3 & 80.7 & 176.4 & 219.5 & 331.3 & 65.4 \\
\hline water & $4-\mathrm{OH}$ & 77.9 & 99.9 & 24.6 & 50.4 & 74.1 & 81.2 & 111.2 & 16.6 & 43.7 & 84.1 \\
\hline ethanol & $4-\mathrm{OH}$ & 77.7 & 105.8 & $\begin{array}{c}19.9 \\
{[p \text {-Coum }]}\end{array}$ & 47.7 & 78.0 & 81.2 & 119.2 & $\begin{array}{l}10.0 \\
p-\mathrm{CA}\end{array}$ & 39.6 & 89.6 \\
\hline gas phase & 4-OH & 67.2 & 78.1 & 305.0 & 394.2 & -11.1 & 81.2 & 184.4 & 212.8 & 326.7 & 70.4 \\
\hline water & $4-\mathrm{OH}$ & 76.8 & 102.2 & 21.1 & 47.4 & 75.9 & 80.9 & 116.8 & 10.7 & 42.0 & 85.6 \\
\hline ethanol & $4-\mathrm{OH}$ & 76.4 & 107.9 & $\begin{array}{c}16.5 \\
{[o-\text {-Coum }]}\end{array}$ & 44.5 & 79.9 & 80.9 & 124.3 & $\begin{array}{l}4.7 \\
o-\mathrm{CA}\end{array}$ & 37.7 & 91.3 \\
\hline gas phase & $2-\mathrm{OH}$ & 76.1 & 81.7 & 310.4 & 405.7 & -13.7 & 80.8 & 187.5 & 209.3 & 328.7 & 68.1 \\
\hline water & $2-\mathrm{OH}$ & 78.4 & 108.3 & 16.6 & 47.5 & 77.5 & 81.3 & 119.8 & 8.1 & 42.0 & 85.9 \\
\hline ethanol & $2-\mathrm{OH}$ & 78.5 & 113.6 & $\begin{array}{c}12.9 \\
{[m-\text {-Coum }]}\end{array}$ & 45.2 & 81.3 & 81.3 & 127.3 & $\begin{array}{l}2.0 \\
m-\mathrm{CA}\end{array}$ & 37.8 & 91.5 \\
\hline gas phase & $3-\mathrm{OH}$ & 78.4 & 80.7 & 313.6 & 398.2 & -3.9 & 84.1 & 190.1 & 210.0 & 336.3 & 63.8 \\
\hline water & $3-\mathrm{OH}$ & 81.9 & 107.4 & 21.1 & 48.3 & 78.7 & 83.4 & 121.9 & 8.2 & 47.1 & 83.0 \\
\hline ethanol & $3-\mathrm{OH}$ & 81.8 & 115.5 & 14.3 & 47.1 & 82.7 & 83.4 & 129.5 & 2.0 & 48.4 & 88.5 \\
\hline
\end{tabular}

nism should be favored for $\mathrm{HCAs}^{-}$when compared to HCA compounds. Furthermore, for both $\mathrm{HCAs}$ and $\mathrm{HCAs}^{-}$, comparison of the IPs of the same species in water and ethanol indicates that this parameter decreases with the surrounding medium polarity. The largest differences among solvents are observed for the acids.

For both $\mathrm{HCA}^{-}$and HCA compounds, the calculated IP values in PCM solvent are significantly larger than the corresponding BDE values, thus indicating that the HAT mechanism is thermodynamically favored compared to SETPT. It is worth noting that although the trends obtained with B3LYP and M06-2X are the same, the IPs for $\mathrm{HCAs}^{-}$and HCAs computed with the M06-2X method are even higher than those obtained with B3LYP (Supporting Information, Tables S58 and S59).

In the gas phase, the IP values for $\mathrm{HCAs}^{-}$are significantly lower than those in polar media, thus indicating that singleelectron abstraction is easier in the absence of the solvent. An opposite behavior is observed for HCAs, showing gas phase IPs higher than those in water or ethanol. The different behavior between HCAs and $\mathrm{HCAs}^{-}$can be reasonably explained by the stabilization of ionic species by polar solvents.

Overall, with the exception of caffeic acid, the IPs of HCAs calculated both in solvent and in the gas phase follow the oxidative trend observed in the DPPH assay. Differently, for $\mathrm{HCAs}^{-}$, the DPPH trend is not followed at all by the IP values in the gas phase, while a better correlation is observed in the presence of solvents.

The second and last step of the SET-PT mechanism is the loss of a proton from the radical formed in the first step, thus it is correlated to the PDE. In water and ethanol, PDE is much lower than the IP. Therefore, the first step of the SET-PT process is considered to be the rate-limiting step. We noted that, somehow counterintuitively, the less polar solvent (ethanol) leads to lower PDE values than the most polar solvent (water). This result is in agreement with the findings obtained with calculations performed at the B3LYP/6-311+ $+\mathrm{g}(\mathrm{d}, \mathrm{p})$ theory level by Chen et al. on similar compounds. ${ }^{25}$

The PDE values in the gas phase are remarkably higher than that in polar media, which suggests that the proton loss is greatly enhanced by the presence of a solvent (see Table 5). It is worthwhile noting that this result is confirmed also at the M06-2X theory level, although the PDEs are smaller than those calculated with B3LYP (Supporting Information, Tables S57S59).

SPLET Mechanism. We investigated the possibility of having a SPLET mechanism by analyzing the PA and the electron transfer enthalpies.

As can be seen in Table 5 and Supporting Information (Figure S16), the PA values of all studied compounds obtained in the gas phase are significantly higher than the ones obtained in water or ethanol, reasonably due to the ion-stabilizing effect of polar solvents.

The $\mathrm{HCA}^{-}$compounds show higher PA values compared to their parent acids in all three studied environments, indicating that this step is more favorable for the acids. This trend is rationalized considering that the loss of a proton from a negatively charged species, leading to a dianion, is less likely than from a neutral species. 
The PAs calculated in water and ethanol for both $\mathrm{HCAs}^{-}$ and HCAs are lower than the BDEs and IPs, revealing that in both solvents, the first step of the SPLET mechanism is thermodynamically favored over HAT and the first step of SET-PT.

The second step of the SPLET mechanism, associated with the ETE parameter, is the rate-limiting step in water and ethanol, as shown by the energy values much higher than the corresponding PAs for all compounds. Furthermore, ETEs of $\mathrm{HCAs}^{-}$are lower than those of HCAs because the singleelectron transfer process from an anion requires lower energy than that from a neutral form. Therefore, $\mathrm{HCAs}^{-}$are more susceptible to the second step of the SPLET mechanism than HCA compounds.

In the gas phase, the ETEs are lower than those in both polar solvents, and for the $\mathrm{HCAs}^{-}$are even negative. This result is due to the lack of stabilization of the dianion in the absence of solvent, which in turns makes the electron transfer very favorable.

By comparing the BDE and the ETE values, we can draw some conclusions, concerning the possible overall mechanism of radical scavenging. In ethanol, the HAT mechanism is thermodynamically favored over SPLET both for the undissociated acids and the corresponding anions, although to a lesser extent for the latter. In water, the thermodynamic favorite mechanism may be different for $\mathrm{HCAs}^{-}$and HCAs. Indeed, the $\mathrm{HCAs}^{-}$ETE values are lower than BDEs, and therefore, the SPLET mechanism may be favored (with exception for the caffeate). Differently, for HCAs, the HAT mechanism seems to be generally favored. ${ }^{31}$ Indeed, it should be noted that the BDE and ETE values for ferulic, sinapic, and $m$-coumaric are similar, and therefore, both mechanisms seem plausible.

\section{CONCLUSIONS}

In this work, six HCAs, poorly water-soluble antioxidant compounds, were converted into ILs containing cholinium cation and hydroxycinnamic-based anion ([Cho][HCA $]$ ILs). All the synthesized ILs and the acidic precursors were evaluated for their solubility, thermal stability, and antioxidant activity. Furthermore, [Cho][HCA] ILs were screened for their cytotoxicity. Compared to the corresponding parent acid, [Cho][HCA] ILs showed notably higher solubility and lower thermal stability, although $T_{\mathrm{D}}$ is above $100{ }^{\circ} \mathrm{C}$. The MTT results pointed out the high biocompatibility of all the salts. Only [Cho][Caff] exhibited marginal cytotoxicity. Furthermore, an improvement in the antioxidant activity was observed for all cholinium salts compared to HCAs, except the $m$-CA/ $[\mathrm{Cho}][m$-Coum $]$ and $o$-CA/ $[\mathrm{Cho}][o$-Coum $]$ pairs showing weak antioxidant activity. The same order of scavenging activity was observed for acids and salts. Finally, to rationalize the experimental trends of the antioxidant activity, DFT calculations were performed on all the intermediates of the considered oxidation paths (HAT, SET-PT, and SPLET) in the gas phase, water, and ethanol. The computational results, obtained using DFT/B3LYP and DFT/M06-2X methods with $6-311++G(d, p)$ basis set, lead to the same conclusions. In particular, comparison of the calculated TPs, typically associated with the abovementioned mechanism (BDE, IP, PDE, PA, and ETE) with the experimental findings, indicated that the HAT mechanism is possible both in ethanol and water for all compounds. The SPLET mechanism is also plausible in both solvents and might even be favored over HAT in water for some of the anions. Differently, the SET-PT is thermodynamically not favorable. Importantly, the energies of the intermediates involved in the radical scavenging mechanism are found to be generally lower for $\mathrm{HCAs}^{-}$ compared to the parent acids, thus explaining their improved antioxidant capability. Overall, the findings of this study suggest that [Cho][HCA] ILs may be good candidates as an alternative to HCAs in the pharmaceutical field. Further studies are underway to analyze the potentials health benefit of these compounds.

\section{ASSOCIATED CONTENT}

\section{Supporting Information}

The Supporting Information is available free of charge at https://pubs.acs.org/doi/10.1021/acssuschemeng.1c00090.

${ }^{1} \mathrm{H}$ and ${ }^{13} \mathrm{C}$ chemical shifts; IR frequency; UV and absorptivity spectra; protonation constants; speciation plots; DSC and TGA curves; thermodynamic indices calculated with $\mathrm{MO} 62 \mathrm{X} / 6-311++\mathrm{G}(\mathrm{d}, \mathrm{p})$; graphics of BDE, IP, PDE, PA, and ETE values; number of conformers for each of the species involved in the possible scavenging mechanism; internal coordinates of global minimum of HCAs, $\mathrm{HCAs}^{-}$, and intermediates in vacuo and polar solvent (PDF)

\section{AUTHOR INFORMATION}

\section{Corresponding Authors}

Francesca Mocci - Department of Chemical and Geological Science, University of Cagliari, I-09042 Monserrato (CA), Italy; orcid.org/0000-0003-1394-9146; Phone: + 39 070 6754390; Email: fmocci@unica.it; Fax: + 39070 6754389

Flaminia Cesare Marincola - Department of Chemical and Geological Science, University of Cagliari, I-09042 Monserrato (CA), Italy; 1 orcid.org/0000-0002-96955957; Phone: + 39070 6754390; Email: flaminia@ unica.it; Fax: + 390706754388

\section{Authors}

Monica Demurtas - Department of Chemical and Geological Science, University of Cagliari, I-09042 Monserrato (CA), Italy

Valentina Onnis - Department of Life and Environmental Sciences, Unit of Pharmaceutical, Pharmacological and Nutraceutical Sciences, University of Cagliari, I-09042 Monserrato (CA), Italy; 이이.org/0000-0002-2438$725 \mathrm{X}$

Paolo Zucca - Department of Biomedical Sciences, University of Cagliari, I-09042 Monserrato (CA), Italy

Antonio Rescigno - Department of Biomedical Sciences, University of Cagliari, I-09042 Monserrato (CA), Italy

Joanna Izabela Lachowicz - Department of Medicinal Sciences and Public Health, Policlinico Universitario, I-09042 Monserrato (CA), Italy; (1) orcid.org/0000-0003-4644$761 X$

Leon De Villiers Engelbrecht - Department of Chemical and Geological Science, University of Cagliari, I-09042 Monserrato (CA), Italy

Mariella Nieddu - Department of Biomedical Sciences, University of Cagliari, I-09042 Monserrato (CA), Italy 
Guido Ennas - Department of Chemical and Geological Science, University of Cagliari, I-09042 Monserrato (CA), Italy

Alessandra Scano - Department of Chemical and Geological Science, University of Cagliari, I-09042 Monserrato (CA), Italy

Complete contact information is available at: https://pubs.acs.org/10.1021/acssuschemeng.1c00090

\section{Author Contributions}

The manuscript was written through contributions of all authors. All authors have given approval to the final version of the manuscript.

\section{Funding}

This work was financially supported by the University of Cagliari (Fondo Integrativo per la Ricerca, FIR 2016-2017), Italian Ministry of Education, University and Research (PRIN 2017, prot. no. 2010E84AA4_002 to V.O. and prot. no. 2017W75RAE to F.M.), Fondazione Banco di Sardegna (Project CUP: F71I17000170002 and F72F20000230007) and Regione Autonoma della Sardegna (RASSR81788-2017).

\section{Notes}

The authors declare no competing financial interest.

\section{ACKNOWLEDGMENTS}

F.M. and M.D. thank Prof. Giuseppe Saba and Andrea Ardu for technical support. F.C.M. and M.D. thank the CeSAR (Centro Servizi Ricerca d'Ateneo) core facility of the University of Cagliari and Dr. Sandrina Lampis for assistance with the generation of NMR data. Parts of the computations were enabled by resources provided by the Swedish National Infrastructure for Computing (SNIC) at NSC CENTRE, partially funded by the Swedish Research Council through grant agreement no. 2016-07213.

\section{REFERENCES}

(1) Davis, H. Task-Specific Ionic Liquids. Chem. Lett. 2004, 33, 1072-1077.

(2) Hough, W. L.; Rogers, R. D. Ionic liquids then and now: From solvents to materials to active pharmaceutical ingredients. Bull. Chem. Soc. Jpn. 2007, 80, 2262-2269.

(3) Pandey, S. Analytical applications of room-temperature ionic liquids: A review of recent efforts. Anal. Chim. Acta 2006, 556, 38-45.

(4) Zhao, D.; Wu, M.; Kou, Y.; Min, E. Ionic liquids: Applications in catalysis. Catal. Today 2002, 74, 157-189.

(5) Plechkova, N. V.; Seddon, K. R. Applications of ionic liquids in the chemical industry. Chem. Soc. Rev. 2008, 37, 123-150.

(6) Egorova, K. S.; Gordeev, E. G.; Ananikov, V. P. Biological Activity of Ionic Liquids and Their Application in Pharmaceutics and Medicine. Chem. Rev. 2017, 117, 7132-7189.

(7) Gadilohar, B. L.; Shankarling, G. S. Choline based ionic liquids and their applications in organic transformation. J. Mol. Liq. 2017, 227, 234-261.

(8) Rengstl, D.; Fischer, V.; Kunz, W. Low-melting mixtures based on choline ionic liquids. Phys. Chem. Chem. Phys. 2014, 16, 2281522822.

(9) El-Seedi, H. R.; El-Said, A. M. A.; Khalifa, S. A. M.; Göransson, U.; Bohlin, L.; Borg-Karlson, A.-K.; Verpoorte, R. Biosynthesis, natural sources, dietary intake, pharmacokinetic properties, and biological activities of hydroxycinnamic acids. J. Agric. Food Chem. 2012, 60, 10877-10895.

(10) Maurya, D. K.; Devasagayam, T. P. A.; Devasagayam, A. Antioxidant and prooxidant nature of hydroxycinnamic acid derivatives ferulic and caffeic acids. Food Chem. Toxicol. 2010, 48, 3369-3373.

(11) Taofiq, O.; González-Paramás, A.; Barreiro, M.; Ferreira, I.; McPhee, D. J. Hydroxycinnamic acids and their derivatives: Cosmeceutical significance, challenges and future perspectives, a review. Molecules 2017, 22, 281.

(12) Wolszleger, M.; Stan, C. D.; Pânzariu, A.; Jitâreanu, A.; Profire, L. New Thiazolidine-4-Ones of ferulic acid with antioxidant potential. Farmacia 2015, 63, 150-154.

(13) Bendary, E.; Francis, R. R.; Ali, H. M. G.; Sarwat, M. I.; El Hady, S. Antioxidant and structure - activity relationships (SARs) of some phenolic and anilines compounds. Ann. Agric. Sci. 2013, 58, 173-181.

(14) Zillich, O. V.; Schweiggert-Weisz, U.; Eisner, P.; Kerscher, M. Polyphenols as active ingredients for cosmetic products. Int. J. Cosmet. Sci. 2015, 37, 455-464.

(15) Mukherjee, P. K.; Maity, N.; Nema, N. K.; Sarkar, B. K. Bioactive compounds from natural resources against skin aging. Phytomedicine 2011, 19, 64-73.

(16) Sintra, T. E.; Luís, A.; Rocha, S. N.; Lobo Ferreira, A. I. M. C.; Gonçalves, F.; Santos, L. M. N. B. F.; Neves, B. M.; Freire, M. G.; Ventura, S. P. M.; Coutinho, J. A. P. Enhancing the antioxidant characteristics of phenolic acids by their conversion into cholinium salts. ACS Sustainable Chem. Eng. 2015, 3, 2558-2565.

(17) Morais, E. S.; Silva, N. H. C. S.; Sintra, T. E.; Santos, S. A. O.; Neves, B. M.; Almeida, I. F.; Costa, P. C.; Correia-Sá, I.; Ventura, S. P. M.; Silvestre, A. J. D.; Freire, M. G.; Freire, C. S. R. Anti-inflammatory and antioxidant nanostructured cellulose membranes loaded with phenolic-based ionic liquids for cutaneous application. Carbohydr. Polym. 2019, 206, 187-197.

(18) Albert, A.; Serjeant, E. P. Determination of Ionization Constants by Spectrophotometry. The Determination of Ionization Constants: A Laboratory Manual; Chapman and Hall: London, 1984; pp 70-95.

(19) Zhou, J.; Sui, H.; Jia, Z.; Yang, Z.; He, L.; Li, X. Recovery and purification of ionic liquids from solutions: a review. RSC Adv. 2018, $8,32832-32864$.

(20) Lachowicz, J. I.; Nurchi, V. M.; Crisponi, G.; JaraquemadaPelaez, M. G.; Arca, M.; Pintus, A.; Santos, M. A.; Quintanova, C.; Gano, L.; Szewczuk, Z.; Zoroddu, M. A.; Peana, M.; DomínguezMartín, A.; Choquesillo-Lazarte, D. Hydroxypyridinones with enhanced iron chelating properties. Synthesis, characterization and in vivo tests of 5-hydroxy-2-(hydroxymethyl)pyridine- 4(1H)-one. Dalton Trans. 2016, 45, 6517-6528.

(21) Grove-Rasmussen, K. V. Determination of the equivalence point in potentiometric acid-base titrations. Dan. Tidsskr. Farm. 1961, $35,236-242$.

(22) Huang, D.; Ou, B.; Prior, R. L. The chemistry behind antioxidant capacity assays. J. Agric. Food Chem. 2005, 53, 18411856.

(23) Rosa, A.; Nieddu, M.; Piras, A.; Atzeri, A.; Putzu, D.; Rescigno, A. Maltese mushroom (Cynomorium coccineum 1.) as source of oil with potential anticancer activity. Nutrients 2015, 7, 849-864.

(24) Foti, M. C. Use and Abuse of the DPPH• Radical. J. Agric. Food Chem. 2015, 63, 8765-8776.

(25) Chen, Y.; Xiao, H.; Zheng, J.; Liang, G. Structurethermodynamics-antioxidant activity relationships of selected natural phenolic acids and derivatives: An experimental and theoretical evaluation. PLoS One 2015, 10, No. e0121276.

(26) Leopoldini, M.; Russo, N.; Toscano, M. The molecular basis of working mechanism of natural polyphenolic antioxidants. Food Chem. 2011, 125, 288-306.

(27) Chen, J.; Yang, J.; Ma, L.; Li, J.; Shahzad, N.; Kim, C. K. Structure-antioxidant activity relationship of methoxy, phenolic hydroxyl, and carboxylic acid groups of phenolic acids. Sci. Rep. 2020, 10, 2611.

(28) Anouar, E.; Calliste, C. A.; Košinová, P.; Di Meo, F.; Duroux, J. L.; Champavier, Y.; Marakchi, K.; Trouillas, P. Free Radical Scavenging Properties of Guaiacol Oligomers: A Combined 
Experimental and Quantum Study of the Guaiacyl-Moiety Role. J. Phys. Chem. A 2009, 113, 13881-13891.

(29) Zheng, Y. Z.; Deng, G.; Liang, Q.; Chen, D. F.; Guo, R.; Lai, R. C. Antioxidant Activity of Quercetin and Its Glucosides from Propolis: A Theoretical Study. Sci. Rep. 2017, 7, 7543.

(30) Xue, Y.; Zheng, Y.; An, L.; Dou, Y.; Liu, Y. Density functional theory study of the structure-antioxidant activity of polyphenolic deoxybenzoins. Food Chem. 2014, 151, 198-206.

(31) Mazzone, G.; Russo, N.; Toscano, M. Antioxidant properties comparative study of natural hydroxycinnamic acids and structurally modified derivatives: Computational insights. Comput. Theor. Chem. 2016, 1077, 39-47.

(32) Rimarčík, J.; Lukeš, V.; Klein, E.; Ilčin, M. Study of the solvent effect on the enthalpies of homolytic and heterolytic $\mathrm{N}-\mathrm{H}$ bond cleavage in p-phenylenediamine and tetracyano-p-phenylenediamine. J. Mol. Struct.: THEOCHEM 2010, 952, 25-30.

(33) Frisch, M. J.; Trucks, G. W.; Schlegel, H. B.; Scuseria, G. E.; Robb, M. A.; Cheeseman, J. R.; Scalmani, G.; Barone, V.; Petersson, G. A.; Nakatsuji, H.; Li, X.; Caricato, M.; Marenich, A. V.; Bloino, J.; Janesko, B. G.; Gomperts, R.; Mennucci, B.; Hratchian, H. P.; Ortiz, J. V.; Izmaylov, A. F.; Sonnenberg, J. L.; Williams-Young, D.; Ding, F.; Lipparini, F.; Egidi, F.; Goings, J.; Peng, B.; Petrone, A.; Henderson, T.; Ranasinghe, D.; Zakrzewski, V. G.; Gao, J.; Rega, N.; Zheng, G.; Liang, W.; Hada, M.; Ehara, M.; Toyota, K.; Fukuda, R.; Hasegawa, J.; Ishida, M.; Nakajima, T.; Honda, Y.; Kitao, O.; Nakai, H.; Vreven, T.; Throssell, K.; Montgomery, J. A., Jr.; Peralta, J. E.; Ogliaro, F.; Bearpark, M. J.; Heyd, J. J.; Brothers, E. N.; Kudin, K. N.; Staroverov, V. N.; Keith, T. A.; Kobayashi, R.; Normand, J.; Raghavachari, K.; Rendell, A. P.; Burant, J. C.; Iyengar, S. S.; Tomasi, J.; Cossi, M.; Millam, J. M.; Klene, M.; Adamo, C.; Cammi, R.; Ochterski, J. W.; Martin, R. L.; Morokuma, K.; Farkas, O.; Foresman, J. B.; Fox, D. J. Gaussian 16, Revision A.03; Gaussian, Inc.: Wallingford CT, 2016.

(34) Cancès, E.; Mennucci, B. Analytical derivatives for geometry optimization in solvation continuum models. J. Chem. Phys. 1998, 109, 249-259.

(35) Cossi, M.; Barone, V.; Mennucci, B.; Tomasi, J. Ab initio study of ionic solutions by a polarizable continuum dielectric model. Chem. Phys. Lett. 1998, 286, 253-260.

(36) Zhao, Y.; Truhlar, D. G. The M06 suite of density functionals for main group thermochemistry, thermochemical kinetics, noncovalent interactions, excited states, and transition elements: two new functionals and systematic testing of four M06-class functionals and 12 other functionals. Theor. Chem. Acc. 2008, 120, 215-241.

(37) Shameera Ahamed, T. K.; Rajan, V. K.; Sabira, K.; Muraleedharan, K. DFT and QTAIM based investigation on the structure and antioxidant behavior of lichen substances Atranorin, Evernic acid and Diffractaic acid. Comput. Biol. Chem. 2019, 80, 6678.

(38) Tošović, J.; Marković, S.; Dimitrić Marković, J. M.; Mojović, M.; Milenković, D. Antioxidative mechanisms in chlorogenic acid. Food Chem. 2017, 237, 390-398.

(39) Dennington, R.; Keith, T. A.; Millam, J. M. GaussView, Version 6; Semichem Inc.: Shawnee Mission, KS, 2016.

(40) Kramer, S. F.; Flynn, G. L. Solubility of organic hydrochlorides. J. Pharm. Sci. 1972, 61, 1896-1904.

(41) Kobayashi, K.; Kimura, M.; Sakoguchi, T.; Hase, A.; Matsuoka, A.; Kaneko, S. Pharmacokinetics of gliclazide in healthy and diabetic subjects. J. Pharm. Sci. 1984, 73, 1684-1687.

(42) Streng, W. H.; Hsi, S. K.; Helms, P. E.; Tan, H. G. H. General treatment of $\mathrm{pH}$-solubility profiles of weak acids and bases and the effects of different acids on the solubility of a weak base. Pharm. Sci. 1984, 73, 1679-1684.

(43) Adams, M. L.; O’Sullivan, B.; Downard, A. J.; Powell, K. J. Stability Constants for Aluminum(III) Complexes with the 1,2Dihydroxyaryl Ligands Caffeic Acid, Chlorogenic Acid, DHB, and DASA in Aqueous Solution. Chem. Eng. Data 2002, 47, 289-296.

(44) Matus, M. H.; Domínguez, Z.; Salas-Reyes, M.; Hernández, J.; Cruz-Sánchez, S. Conformational study of caffeic acid derivatives. J. Mol. Struct.: THEOCHEM 2010, 953, 175-181.
(45) Kontogianni, V. G.; Charisiadis, P.; Primikyri, A.; Pappas, C. G.; Exarchou, V.; Tzakos, A. G.; Gerothanassis, I. P. Hydrogen bonding probes of phenol $-\mathrm{OH}$ groups. Org. Biomol. Chem. 2013, 11, 1013-1025.

(46) Lachowicz, J. I.; Nurchi, V. M.; Crisponi, G.; Pelaez, M. d. G. J.; Rescigno, A.; Stefanowicz, P.; Cal, M.; Szewczuk, Z. Metal coordination and tyrosinase inhibition studies with Kojic- $\beta$ Ala-Kojic. J. Inorg. Biochem. 2015, 151, 36-43.

(47) Mota, F. L.; Queimada, A. J.; Pinho, S. P.; Macedo, E. A. Aqueous solubility of some natural phenolic compounds. Ind. Eng. Chem. Res. 2008, 47, 5182-5189.

(48) Queimada, A. J.; Mota, F. L.; Pinho, S. P.; Macedo, E. A. Solubilities of biologically active phenolic compounds: measurements and modeling. J. Phys. Chem. B 2009, 113, 3469-3476.

(49) Nurchi, V. M.; Pivetta, T.; Lachowicz, J. I.; Crisponi, G. Effect of substituents on complex stability aimed at designing new iron(III) and aluminum(III) chelators. J. Inorg. Biochem. 2009, 103, 227-236.

(50) Dalla Torre, G.; Mujika, J. I.; Lachowicz, J. I.; Ramos, M. J.; Lopez, X. The interaction of aluminum with catecholamine-based neurotransmitters: Can the formation of these species be considered a potential risk factor for neurodegenerative diseases? Dalton Trans. 2019, 48, 6003-6018.

(51) Lachowicz, J. I.; Nurchi, V. M.; Crisponi, G.; JaraquemadaPelaez, M. d. G.; Ostrowska, M.; Jezierska, J.; Gumienna-Kontecka, E.; Peana, M.; Zoroddu, M. A.; Choquesillo-Lazarte, D.; NiclósGutiérrez, J.; González-Pérez, J. M. Zinc(II) and copper(II) complexes with hydroxypyrone iron chelators. J. Inorg. Biochem. 2015, 151, 94-106.

(52) Alevizou, E. I.; Voutsas, E. C. Solubilities of p-coumaric and caffeic acid in ionic liquids and organic solvents. J. Chem. Thermodyn. 2013, 62, 69-78.

(53) Gurvich, L. V.; Veyts, I. V.; Alcock, C. B. Thermodynamic Properties of Individual Substances, 4th ed.; Hemisphere Publishing Corporation, 1990.

(54) Rice-Evans, C. A.; Miller, N. J.; Paganga, G. Structure antioxidant activity relationships of flavonoids and phenolic acids. Free Radical Biol. Med. 1996, 20, 933-956.

(55) Alicja, U.; Marcin, M.; Małgorzata, S. Quantum-chemical Calculations of the Antioxidant Properties of trans- p-coumaric Acid and trans-sinapinic Acid. Comput. Methods Sci. Technol. 2012, 18, 117-128.

(56) Lithoxoidou, A. T.; Bakalbassis, E. G. Liquid-Phase Theoretical Antioxidant Activity Trend of Some Cinnamic Acid Antioxidants. J. Am. Oil Chem. Soc. 2004, 81, 799-802.

(57) Szeląg, M.; Urbaniak, A.; Bluyssen, H. A. R. A theoretical antioxidant pharmacophore for natural hydroxycinnamic acids. Open Chem. 2015, 13, 17-31.

(58) Amić, A.; Marković, Z.; Klein, E.; Dimitrić Marković, J. M.; Milenković, D. Theoretical study of the thermodynamics of the mechanisms underlying antiradical activity of cinnamic acid derivatives. Food Chem. 2018, 246, 481-489.

(59) Galano, A.; Mazzone, G.; Alvarez-Diduk, R.; Marino, T.; Alvarez-Idaboy, J. R.; Russo, N. Food Antioxidants: Chemical Insights at the Molecular Level. Ann. Rev. Food Sci. Technol. 2016, 7, 335-352.

(60) Biela, M.; Poliak, P.; Kleinová, A.; Lukeš, V.; Klein, E. On the Thermodynamics of antioxidant action of naturally occurring hydroxyderivatives of cis -cinnamic acid. J. Serbian Soc. Comput. Mech. 2020, 36, 26-36. 